\title{
Analisis Kebijakan Struktur Tarif dan Pengaruhnya terhadap Besaran Subsidi (Studi Kasus : TransJakarta)
}

\author{
Analysis of Tariff Structure Policy and Its Impact to the Amount of \\ Subsidy (Case Study : TransJakarta)
}

\author{
Mira Lestira Hariani ${ }^{1, \text { a) }}$, Idwan Santoso ${ }^{2, b)}$ \& Sony Sulaksono Wibowo ${ }^{2, c)}$ \\ ${ }^{1)}$ Program Studi Teknik Sipil, Universitas Swadaya Gunung Djati, Cirebon. \\ ${ }^{2)}$ Program Magister Teknik Sipil, Institut Teknologi Bandung, Bandung.
}

Koresponden : ${ }^{a)}$ mira.hariani0103@gmail.com, ${ }^{b}$ idwan2003@yahoo.com \& ${ }^{c)}$ sonyssw@si.itb.ac.id

\begin{abstract}
ABSTRAK
Kebijakan tarif angkutan umum merupakan komponen dasar yang sangat penting dalam pengoperasian angkutan umum karena tarif merupakan faktor utama dalam menarik penumpang dan sangat berpengaruh terhadap kondisi finansial operator angkutan umum. Penerapan kebijakan struktur tarif seragam/flat fare pada Transjakarta seakan-akan tidak memperhatikan karakteristik pergerakan penumpang sehingga dengan penerapan struktur tarif yang dipengaruhi oleh jarak dapat memberikan peluang untuk menghasilkan revenue yang lebih besar dan berimplikasi terhadap penurunan besaran subsidi. Penelitian ini bertujuan untuk melakukan kajian terhadap pengembangan beberapa alternatif kebijakan struktur tarif yang dapat diterapkan oleh Transjakarta dan kemudian memberikan rekomendasi kebijakan struktur tarif yang dapat berpengaruh terhadap penurunan besaran subsidi dengan tetap memperhatikan kemampuan membayar pengguna dan kenyamanan pengguna atas perubahan tarif yang terjadi. Dalam penelitian ini menggunakan analisis ability to pay dalam penentuan besaran tarif dan menggunakan data tapping Transjakarta pada tanggal 18 Mei 2018 yang diolah menjadi data distribusi frekuensi penumpang sebagai dasar dalam perhitungan revenue Transjakarta untuk setiap alternatif kebijakan yang dirumuskan. Dengan melakukan evaluasi terhadap 7 (tujuh) alternatif yang telah dirumuskan maka diperoleh hasil bahwa kebijakan yang paling direkomendasikan adalah struktur tarif bertahap (sectional fare) dengan kebijakan tarif awal sebesar Rp.3.500 berlaku pada 15 kilometer pertama kemudian berlaku tarif penyesuaian sebesar Rp.1.500 untuk setiap pertambahan jarak 10 kilometer. Kebijakan tersebut menghasilkan penurunan subsidi sebesar Rp.34.476.000/hari atau sekitar 10,71\% jika dibandingkan dengan tarif eksisting Transjakarta.
\end{abstract}

Kata Kunci : manajemen fasilitas, angkutan umum, kebijakan tarif angkutan umum, struktur tarif, transjakarta, subsidi.

\section{PENDAHULUAN}

PT. Transportasi Jakarta bertanggung jawab dalam memberikan layanan angkutan umum Transjakarta di Provinsi DKI Jakarta dan berperan sebagai kepanjangan tangan dari pemerintah dimana PT. Transportasi Jakarta tidak berada pada posisi untuk meraup keuntungan yang sebesar-besarnya dengan adanya intervensi penuh dari pemerintah dalam penetapan kebijakan tarif Transjakarta. Adanya intervensi tersebut berimplikasi terhadap kurangnya revenue yang diperoleh dari pengoperasian Transjakarta jika dibandingkan dengan biaya produksi yang dikeluarkan oleh PT. Transportasi Jakarta. Karena pemerintah telah berkomitmen untuk memberikan layanan angkutan umum yang baik, maka sebagai konsekuensi dari intervensi 
yang telah dilakukan pemerintah memberikan dukungan dalam bentuk pemberian subsidi kepada PT. Transportasi Jakarta agar operasional Transjakarta tetap bisa berjalan. Adapun besaran subsidi yang diberikan merupakan selisih antara biaya produksi yang dikeluarkan dengan total revenue yang diperoleh dari pengoperasian Transjakarta. Dengan melihat konsep tersebut, maka dapat disimpulkan bahwa besaran subsidi sangat dipengaruhi oleh total revenue yang diperoleh, sedangkan total revenue sangat dipengaruhi oleh karakteristik pergerakan penumpang serta struktur tarif yang diterapkan.

Seiring dengan semakin banyaknya moda angkutan umum lain yang mulai beroperasi di DKI Jakarta, maka sudah seharusnya PT. Transportasi Jakarta mulai mengembangkan strategi dalam menghadapi kemungkinan adanya pengurangan subsidi yang diberikan pemerintah. Strategi yang paling mungkin untuk dilakukan adalah dengan cara pengaturan sistem tarif TransJakarta, baik dalam hal besaran maupun jenis struktur tarifnya. Struktur tarif yang saat ini diterapkan oleh TransJakarta adalah struktur tarif flat dimana pada struktur flat seakan-akan hanya memperhatikan jumlah penumpang tetapi tidak memperhatikan karakterisitik pergerakan penumpangnya dan tidak memanfaatkan adanya potensi keuntungan dari penumpang jarak jauh. Padahal, jika karakteristik pergerakan penumpang diperhatikan maka dapat dikembangkan beberapa kebijakan struktur tarif lain yang berpotensi untuk dapat meningkatkan total revenue TransJakarta.

Layanan angkutan umum Bus Rapid Transit (BRT) TransJakarta sebagai Fasiilitas Kota Jakarta perlu untuk dikelola dengan baik, agar selalu bisa berfungsi dengan baik secara ekonomis (Soemitro \& Suprayitno, 2018). Beberapa aspek Angkutan Kota Bus Perkotaan telah dibahas, seperti misalnya : perilaku perjalanan (Upa, Suprayitno \& Ryansyah, 2018) dan Bis Sekolah (Muhtadi, Wasono, Suprayitno \& Ahyudanari, 2019). Salah satu aspek yang harus dikelola dengan baik adalah Tarif TransJakata.

Oleh karena itu, analisis Kebijakan Struktur Tarif TransJakarta sangat penting untuk dilakukan guna mendapatkan Kebijakan Struktur Tarif yang dapat meingkatkan total revenue TransJakarta dan dapat berimplikasi terhadap penurunan besaran subsidi.

\section{Gambaran Umum Tarif Angkutan Umum}

Tarif angkutan umum adalah harga jasa angkutan yang harus dibayar oleh pengguna jasa, baik melalui mekanisme perjanjian sewa menyewa, tawar menawar, maupun ketetapan pemerintah (Warpani, 2002). Dalam merencanakan tarif pada suatu sistem angkutan umum, sangat penting untuk memperhatikan tujuan dari perencanaan tarif tersebut (Vuchic, 2005). Beberapa tujuan dasar dari sistem tarif adalah menarik jumlah penumpang maksimum, menghasilkan pendapatan maksimum bagi operator angkutan umum dan mencapai tujuan yang lebih spesifik, seperti meningkatkan mobilitas pekerja, siswa, atau orang tua, meningkatkan akses pada area-area tertentu, mempromosikan penggunaan moda angkutan umum yang lebih efisien, dan lain-lain.

Secara konseptual, tarif angkutan umum terdiri dari 2 (dua) komponen penting yaitu cost (biaya) dan revenue (pendapatan). Jika tidak ada keseimbangan antara besaran biaya dan pendapatan, maka perlu dilakukan suatu strategi dalam menyeimbangkan rasio biaya dan pendapatan. Apabila besaran cost lebih besar dari revenue, maka besarnya revenue bisa ditingkatkan dengan adanya pemberian subsidi dari pemerintah. Apabila besaran subsidi tersebut terbatas pada besaran tertentu dan masih belum bisa menutupi komponen biaya yang dikeluarkan operator (operator mengalami defisit), maka terdapat 2 (dua) cara dalam mengatasi permasalahan tersebut. Pertama, dengan cara mengurangi biaya produksi angkutan umum agar besaran cost berkurang seperti mengurangi cicilan bank (fixed cost) atau mengurangi biaya maintenance. Kedua, dengan cara mengatur tarif angkutan umum agar revenue meningkat seperti meningkatkan besaran tarif atau mengatur struktur tarifnya. 
Struktur tarif dapat dibedakan berdasarkan karakteristik spasial, temporal dan demografi. Struktur tarif berdasarkan karakteristik spasial diklasifikasikan berdasarkan hubungan antara jumlah tarif dan jarak yang ditempuh di jalur angkutan umum. Dengan menggunakan kriteria tersebut, maka terdapat dua struktur utama dari struktur tarif berdasarkan karakteristik spasial yaitu tarif seragam/flat fare dan graduated fare, yang kemudian terbagi lagi menjadi tarif bertahap/sectional fare dan tarif berdasarkan zona/zonal fare.

\section{Struktur Tarif Seragam / Flat Fare Structure}

Pada tarif seragam/flat fare, tarif tetap konstan terlepas dari jarak perjalanan penumpang pada satu kendaraan atau di seluruh jaringan angkutan umum. Tarif seragam merupakan tarif yang paling sederhana yang mana struktur tarif tersebut memberikan kemudahan bagi penumpang untuk mengerti dan menggunakannya. Kerugian mendasar pada struktur tarif seragam adalah kurangnya keadilan bagi pengguna angkutan umum, khususnya bagi pengguna dengan jarak perjalanan yang dekat.

\section{Struktur Tarif Zona / Zonal Fare Structure}

Metode paling sederhana untuk menentukan tarif yang proporsional dan sesuai dengan jarak perjalanan penumpang adalah dengan cara membagi suatu kota atau daerah perkotaan menjadi beberapa zona, kemudian satu tarif berlaku untuk perjalanan penumpang dalam satu zona, tarif yang tinggi diterapkan pada penumpang yang melintas dari satu zona ke zona lain, tarif yang lebih tinggi lagi diterapkan pada penumpang yang melintasi dua batas zona atau lebih. Keuntungan pertama dalam struktur tarif berdasarkan zona adalah struktur tarif tersebut menyediakan tarif dasar seragam untuk suatu wilayah geografis tertentu, serta jumlah pendapatan yang lebih tinggi untuk perjalanan yang lebih panjang. Namun demikian, struktur tarif berdasarkan zona memliki kompleksitas yang lebih besar dalam hal pengumpulan tarif dan kontrol pembayaran tarif. Kerugian pada struktur tarif berdasarkan zona adalah tidak proposionalnya biaya tarif tinggi yang berlaku untuk penumpang dengan jarak perjalanan dekat melintasi batas-batas zona.

\section{$\underline{\text { Struktur Tarif Bertahap / Sectional Fare Structure }}$}

Salah satu cara untuk membuat tarif yang terkait dengan jarak perjalanan adalah dengan membagi jalur angkutan umum menjadi beberapa bagian. Tarif kemudian berubah sesuai dengan jumlah bagian atau section yang dilalui. Biasanya section dibuat lebih pendek dan kenaikan tarif dibuat lebih kecil daripada diameter zona, sehingga tarif bertahap ini lebih terkait erat dengan jarak perjalanan dibandingkan dengan tarif berdasarkan zona. Di sisi lain, tarif bertahap ini memiliki kelemahan yaitu lebih sulit dalam menghitung, mengumpulkan dan mengontrol pembayaran dibandingkan dengan tarif seragam maupun tarif berdasarkan zona.

\section{Kebijakan Tarif Angkutan Umum}

Menurut Warpani (2002), kebijakan tarif dapat dipandang sebagai kebijakan multisisi, di satu sisi dapat dipandang sebagai alat pengendali lalu lintas, di sisi yang lain dapat berarti alat untuk mendorong masyarakat mengunakan kendaraan umum dan mengurangi pengunaan kendaraan pribadi, dan sisi yang lainnya lagi dapat digunakan untuk mengarahkan perkembangan wilayah dan kota. Dalam melakukan perubahan kebijakan tarif dari suatu struktur tarif menjadi struktur yang berbeda tentunya akan memberikan suatu dampak yaitu adanya perubahan pada kinerja angkutan umum. perubahan kebijakan tarif dari tarif flat ke tarif yang berbeda, maka kinerja angkutan umum (penumpang, pendapatan, dan penumpang$\mathrm{km}$ ) bervariasi sesuai dengan elastisitas permintaan. Perubahan kinerja angkutan umum akan menurun dengan peningkatan elastisitas tarif di pasar dengan harga yang lebih tinggi. Sebaliknya, perubahan kinerja angkutan umum akan meningkat dengan penurunan elastisitas tarif di pasar dengan harga yang lebih tinggi (Ling, 1998). Hasil penelitian yang dilakukan oleh 
Daskin dkk (1988) menyatakan bahwa elastisitas permintaan sangat bergantung pada jarak. Semakin panjang jarak perjalanan, semakin kecil elastisitas permintaan, maka struktur tarif graduated dapat memaksimalkan total pendapatan kotor.

Penggunaan struktur tarif didominasi oleh struktur tarif seragam. Struktur tarif seragam diterapkan oleh sekitar 70\% dari keanggotaan UITP yang berpusat pada daerah Euro-Sentris. Sedangkan untuk tarif berdasarkan zona dan tarif bertahap atau berdasarkan jarak hanya diterapkan pada sepertiga kasus saja (Beasley \& Grimsey, 1991). Sedangkan di kota-kota Amerika Utara, banyak operator angkutan umum yang menerapkan struktur tarif seragam untuk bus kota dan layanan kereta bawah tanah tanpa memandang jarak perjalanan atau moda (Cervero, 1980). Penggunaan struktur tarif seragam tersebut tidak selalu sesuai dan menguntungkan jika dilihat dari tingkat kesetaraan sosial bagi pengguna. Dalam penelitian yang dilakukan oleh Glaeser dkk (2008) menganalisis bahwa penduduk berpenghasilan rendah di kota-kota Amerika Utara cenderung tinggal di lingkungan pusat kota yang dilayani dengan baik oleh angkutan umum dimana penduduk ini mungkin melakukan perjalanan jarak yang lebih pendek sehingga merasa dirugikan dengan penerapan struktur tarif seragam.

Dalam penelitian lain mengatakan bahwa kereta komuter cenderung menerapkan struktur tarif berdasarkan zona dan sebagian besar digunakan oleh pekerja dengan tingkat ekonomi tinggi (Taylor \& Morris, 2015). Skema ini juga berlaku untuk Montreal, di mana satu tarif seragam digunakan untuk bus dan metro kota, tetapi tarif kereta komuter adalah berdasarkan zona (Verbich \& Ahmed, 2015).

Kebijakan penerapan struktur tarif sangat erat hubungannya dengan kesetaraan sosial, khususnya dari sisi pengguna angkutan umum. Penggunaan sistem tarif angkutan umum di Montreal yang menerapkan tarif yang lebih tinggi untuk jumlah naik yang lebih sedikit mengakibatkan masyarakat yang tinggal di lingkungan terpinggirkan atau berpenghasilan rendah cenderung lebih banyak mengeluarkan total ongkos untuk angkutan umum dalam sebulan dibandingkan mereka yang berpenghasilan menengah hingga tinggi (Verbich \& Ahmed, 2015). Dalam literatur lainnya mengatakan bahwa strategi stuktur tarif progresif merupakan struktur tarif yang paling diinginkan jika dilihat dari kesejahteraan sosial tertinggi dan permintaan penumpang (Liu, dkk., 2017).

Dalam menetapkan kebijakan struktur tarif, banyak faktor yang perlu dipertimbangkan. Operator angkutan umum yang menghadapi kekurangan anggaran harus mempertimbangkan dilakukannya kenaikan tarif tetapi harus mampu menganalis dampak yang akan terjadi atas kenaikan tarif tersebut. Kebijakan tarif yang meningkatkan biaya transfer menghasilkan dampak yang sangat tidak adil pada berbagai kelompok pelanggan. Alternatif tarif rata-rata per perjalanan merupakan struktur tarif yang paling tidak adil dari seluruh alternatif, bahkan ketika tarif dasar diturunkan. Alternatif yang mempertahankan instrumen struktur tarif yang saat ini dan memungkinkan biaya transfer yang rendah adalah alternatif yang paling banyak disukai (Nuworsoo et al., 2009).

\section{METODE PENELITIAN}

\section{Metode Pengumpulan Data}

Metode pengumpulan data yang digunakan dalam penelitian ini terdiri dari 3 cara sebagai berikut :

1. Wawancara, yaitu mendapatkan data dengan melakukan komunikasi secara langsung maupun melalui alat komunikasi dengan bagian-bagian terkait di dalam PT.Transportasi Jakarta seperti pihak manajemen atau pekerja.

2. Observasi, yaitu mengumpulkan data dengan cara mengamati aktivitas-aktivitas yang terjadi di PT.Transportasi Jakarta untuk mendapatkan data berupa gambaran yang nyata pada bagian-bagian terkait di Operator. 
3. Survey Sekunder, yaitu melakukan pengumpulan data-data sekunder terkait penelitian yang dikaji dan mengolah data tersebut sesuai dengan kebutuhan penelitian.

Adapun data-data yang dibutuhkan dalam penelitian ini bisa dibagi kedalam 4 golongan sebagai berikut.

1. Data Variabel Sosio-Ekonomi DKI Jakarta.

2. Data tap in dan tap out Transjakarta

3. Data Jaringan / Rute Transjakarta

4. Data Kebijakan Operasional Transjakarta Tahun 2018 dan Data Komponen Biaya Pokok Armada (BPA)

\section{Metode Analisis Data}

Metode analisis yang digunakan dalam penelitian ini adalah metode analisis deskriptif kuantitatif, dimana data-data yang diperoleh akan diolah dalam bentuk angka-angka kemudian secara deskriptif akan dijabarkan dan menghasilkan rekomendasi kebijakan struktur tarif yang sesuai untuk diterapkan pada Transjakarta. Analisis yang dilakukan dalam penelitian ini akan dijabarkan sebagai berikut:

Analisis Biaya Produksi

Dalam perhitungan biaya pokok armada mengacu kepada Keputusan Dirjen Perhubungan Darat No. SK 687/AJ 206/DRDJ/2002 tentang Pedoman Teknis Penyelenggaraan Angkutan Penumpang Umum di Wilayah Perkotaan Dalam Trayek Tetap dan Teratur. Adapun komponen-komponen biaya pokok yang dihitung adalah sebagai berikut:

1. Biaya tetap (fixed cost)

a. Biaya modal kendaraan

b. Biaya penyusutan/depresiasi

c. Biaya administrasi

d. Biaya awak kendaraan (pengemudi dan petugas on board)

2. Biaya tidak tetap (running cost)

a. Biaya bahan bakar

b. Biaya pemakaian ban

c. Biaya perawatan dan perbaikan kendaraan

3. Biaya overhead

Berdasarkan Peraturan Presiden no. 54 pasal 66 menyatakan bahwa biaya overhead yang di anggap wajar bagi penyedia adalah $10 \%$ hingga $15 \%$. Namun dalam menentukan persentasi biaya overhead tentunya tergantung dari ketentuan dan keperluan yang ada pada masing-masing penyedia. Dalam penelitian ini diambil angka persentasi maksimal, yaitu $15 \%$ dari total biaya pokok yang telah dihitung.

\section{Analisis Karakteristik Perjalanan Penumpang TransJakarta}

Analisis karakteristik perjalanan penumpang ini terbagi menjadi 2 (dua) tahapan, yaitu analisis terhadap data jaringan/rute Transjakarta untuk mengetahui besaran jarak dari satu stasiun BRT ke stasiun BRT lainnya yang kemudian akan menghasilkan data matriks jarak (MAT Jarak) dari seluruh stasiun BRT Transjakarta yang dikaji. Tahap kedua, yaitu melakukan analisis pada data Tapping yang akan diperoleh dari PT.Transportasi Jakarta dengan tujuan untuk mengetahui frekuensi perjalanan penumpang Transjakarta yang kemudian akan menghasilkan data MAT frekuensi perjalanan penumpang. Gambaran umum Proses analisis karakteristik perjalanan penumpang dapat dilihat pada Gambar 1. 


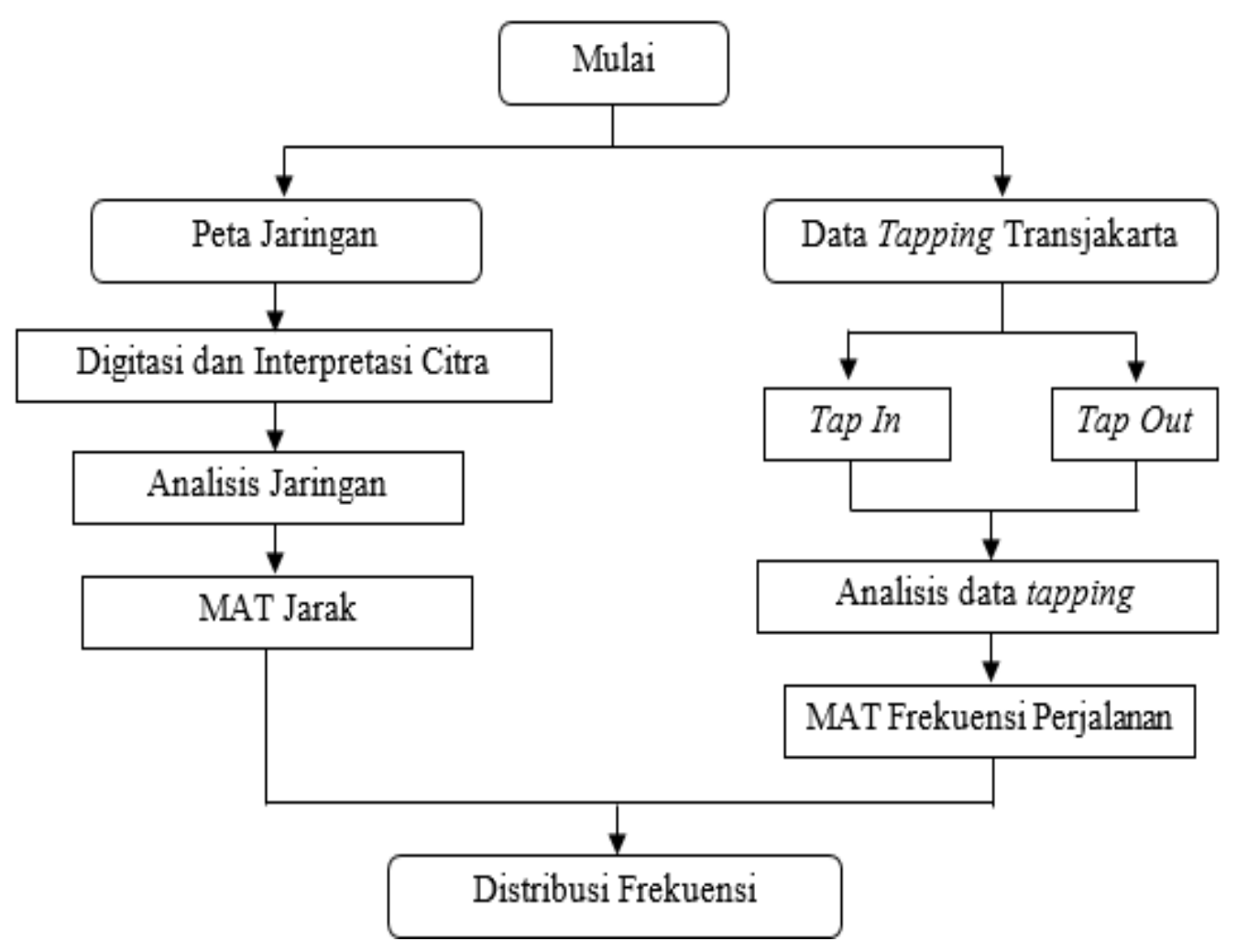

Gambar 1. Gambaran Umum Analisis Karakteristik Pergerakan Penumpang Transjakarta

\section{Analisis Ability to Pay}

Analisis ability to pay (ATP) bertujuan untuk mendapatkan besaran tarif per kilometer yang akan digunakan dalam analisis. Pendekatan yang digunakan dalam analisis ATP didasarkan pada alokasi biaya untuk transportasi dan total pendapatan yang diterimanya (Tamin, dkk.,1999). Dalam menentukan nilai ability to pay dipengaruhi oleh beberapa faktor sebagai berikut:

1. Pendapatan per bulan

2. Kebutuhan Transportasi

3. Jenis Kegiatan

4. Persentase biaya untuk transportasi

5. Intensitas perjalanan

6. Total pengeluaran untuk transportasi

7. Pengeluaran total per bulan

Berdasarkan faktor-faktor tersebut, dapat dikembangkan suatu model yang akan digunakan sebagai pendekatan dalam menentukan nilai ATP. Dalam penelitian ini, faktorfaktor yang dijadikan pendekatan dalam analisis ATP adalah total pendapatan per bulan, persentase biaya untuk transportasi serta intensitas perjalanan penumpang dalam satuan km.pnp/bulan sehingga model yang digunakan dalam analisis ATP adalah sebagai berikut. Model ini sengaja dirumuskan atau dibangun untuk keperluan penelitian ini.

$$
A T P=\frac{\text { Pendapatan } / \text { Bulan } \times \text { Persentase Biaya untuk Transportasi }}{\text { Jumlah } k m \cdot \text { Pnp } / \text { Bulan }}
$$

Pendapatan per bulan yang digunakan adalah merupakan hasil survey Kebutuhan Hidup Layak (KHL) yang dilakukan oleh Dewan Pengupahan Provinsi DKI Jakarta pada periode Bulan Agustus - Oktober 2018 di 16 titik pasar tradisional dimana hasilnya adalah Rp. 3.908.020,-. Untuk jumlah kilometer penumpang per bulan (km.pnp/bulan) merupakan hasil 
kali antara jarak perjalanan rata-rata penumpang dalam kilometer dengan jumlah perjalanan dalam satu bulan. Adapun jumlah perjalanan dalam satu bulan merupakan hasil kali antara jumlah trip per hari (2 kali untuk pergi dan pulang) dengan jumlah hari dalam satu bulan yaitu 30 hari. Dalam menentukan persentase biaya transportasi didasarkan pada studi yang dilakukan oleh Yulia Dewita, dkk (2017) terkait pendekatan baru dalam mengukur transport affordability di 3 (tiga) wilayah metropolitan Indonesia yaitu Jakarta Metropolitan Area (JMA), Bandung Metropolitan Area (BMA) dan Medan Metropolitan Area (MMA) dengan menggunakan data hasil survey ekonomi nasianal (SUSENAS) tahun 2014 yang dilakukan oleh Badan Pusat Statistik. Dalam studi tersebut, besarnya transport affordability index dihitung sebagai persentase biaya transportasi terhadap total pengeluaran rumah tangga. Adapun hasil dari penelitian tersebut mengatakan bahwa pengeluaran rumah tangga di tiga wilayan metropolitan Indonesia umumnya menghabiskan sekitar $10-15 \%$ untuk transportasi dari total pengeluaran sehingga pada penelitian ini menggunakan persentase maksimal sebesar 15\%. Gambaran umum Proses analisis ability to pay dapat dilihat pada Gambar 2.

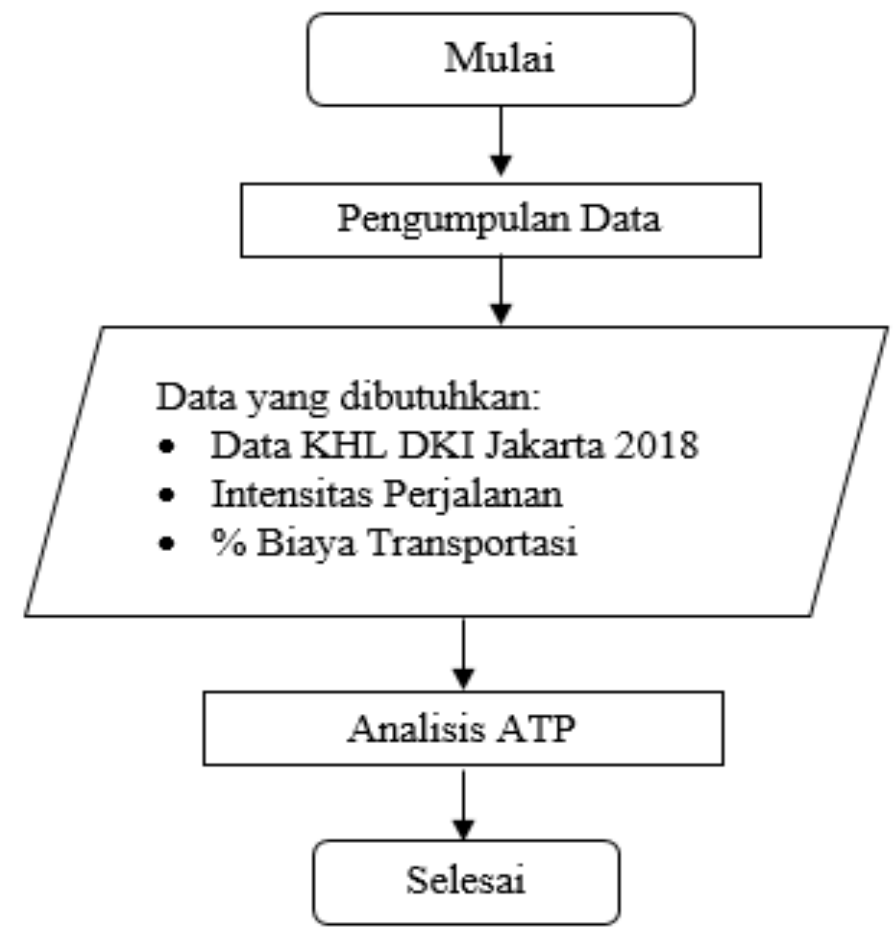

Gambar 2. Gambaran Umum Analisis Ability to Pay

\section{Perumusan Alternatif Kebijakan dan Perhitungan Revenue}

Dalam analisis ini akan dirumuskan beberapa alternatif kebijakan struktur tarif berdasarkan karakteristik spasial dan dihitung revenue pada masing-masing alternatif struktur tarif yang telah dirumuskan berdasarkan data distribusi frekuensi perjalanan penumpang Transjakarta dan besaran tarif yang telah diperoleh dari analisis ATP. Penerapan nilai ATP pengguna dalam rupiah per kilometer ke dalam grafik tarif terhadap jarak akan menghasilkan nilai besaran tarif maksimal yang mampu dibayarkan oleh pengguna Transjakarta. Besaran tarif tersebut menjadi batasan (constrain) dalam perumusan alternatif dimana besarnya tarif pada jarak terjauh tidak boleh melebihi tarif maksimal yang telah ditetapkan dengan tujuan agar kebijakan struktur tarif yang dihasilkan tetap sesuai dengan kemampuan pengguna. Setelah alternatif kebijakan telah dirumuskan, maka berikutnya dihitung besarnya revenue untuk masing-masing alternatif struktur tarif yang kemudian hasilnya akan dievaluasi sehingga dapat menghasilkan kebijakan yang paling baik. Gambaran umum dalam perhitungan revenue dapat dilihat pada Gambar 3. 


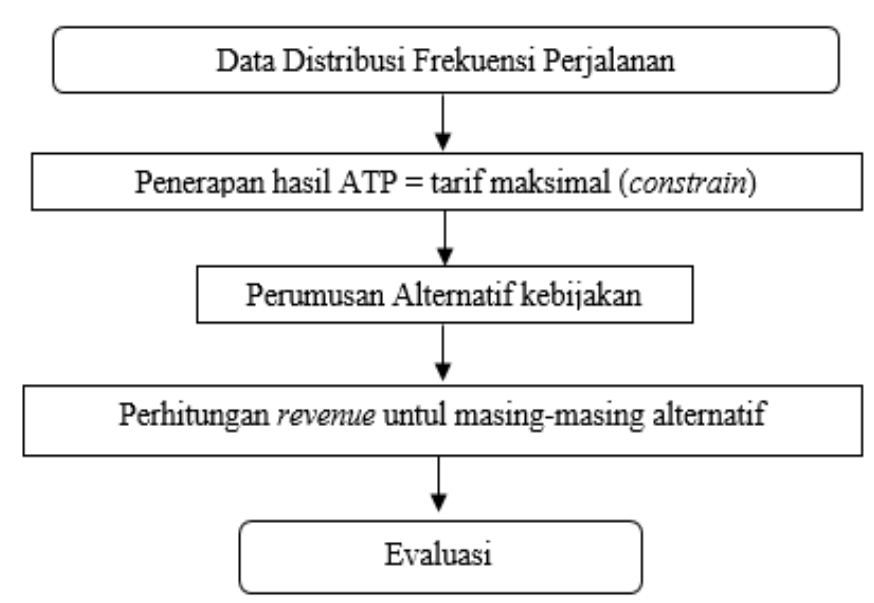

Gambar 3. Gambaran Umum Perhitungan Total Revenue

\section{ANALISIS PENELITIAN}

\section{Analisis Biaya Produksi}

Jenis armada yang beroperasi di koridor $1-13$ Transjakarta terdiri dari berbagai jenis. Akan tetapi pada penelitian ini, dalam perhitungan biaya pokok armada untuk masing-masing koridor yang ditinjau diasumsikan bahwa jenis armada yang beroperasi di semua koridor hanya 1 (satu) jenis saja yaitu bus Mercedes Benz OH-1526 tahun 2016 milik PT.Transportasi Jakarta.

Berdasarkan hasil analisis diperoleh hasil bahwa total biaya produksi pada koridor 1 - 13 Transjakarta adalah sebesar Rp.529.637.182/hari. Dalam perhitungan besaran subsidi menggunakan mekanisme cost recovery, besaran subsidi merupakan selisih antara total revenue dengan total biaya produksi ditambah keuntungan operator. Dengan asumsi PT.Transportasi Jakarta diberikan keuntungan sebesar 10\% dari pengoperasian Transjkarta, maka besarnya biaya produksi ditambah dengan keuntungan yang dijadikan acuan dalam penetapan besaran subsidi adalah sebsar Rp. 582.600.901/hari.

\section{Analisis Karakteristik Perjalanan Penumpang Transjakarta}

Dengan menggunakan MAT jarak untuk seluruh asal - tujuan dan MAT frekuensi yang dibuat berdasarkan data tapping Transjakarta selama 1 (satu) hari penuh pada tanggal 18 Mei 2018 dapat dibuat data distribusi frekuensi perjalanan penumpang Transjakarta yang dapat dilihat pada Gambar 4.

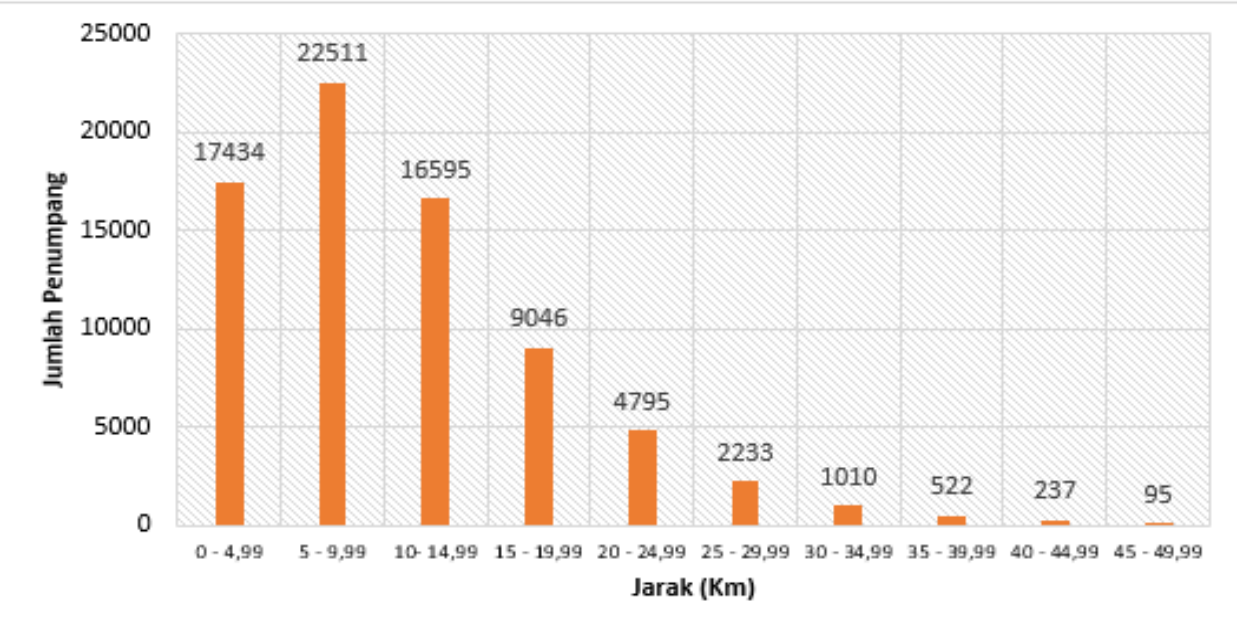

Gambar 4. Distribusi Frekuensi Penumpang Transjakarta 
Berdasarkan data distribusi frekuensi Penumpang Transjakarta di atas, dapat dilihat bahwa untuk karakteristik perjalanan Penumpang Transjakarta, perjalanan jarak dekat lebih banyak daripada perjalanan jauh dengan rata-rata jarak perjalanan sebesar 10,93 kilometer.

Gambar 5 menunjukan perbandingan antara struktur tarif flat dan struktur tarif berdasarkan jarak jika diterapkan oleh Transjakarta. Garis berwarna orange menunjukan penerapan struktur tarif flat yang saat ini diterapkan oleh Transjakarta yaitu sebesar Rp.3.500 dan bernilai konstan sepanjang jarak perjalanan, sedangkan garis abu-abu (grey) menunjukan penerapan struktur tarif berdasarkan jarak. Titik pertemuan antara garis yang menggambarkan penerapan struktur tarif flat dan struktur tarif berdasarkan jarak tersebut merupakan batas yang menggambarkan jarak dimana besaran tarif yang dibayar pada penerapan struktur tarif berdasarkan jarak bernilai sama dengan tarif yang dibayar pada penerapan struktur tarif flat yaitu Rp.3.500. Berdasarkan gambar tersebut dapat terlihat bahwa jarak dimana besaran tarif yang dibayar pada penerapan struktur tarif berdasarkan jarak dan struktur tarif flat bernilai sama adalah pada jarak 7 kilometer. Berdasarkan jumlah penumpang Transjakarta pada data distribusi frekuensi dan jarak batas 7 kilometer maka diperoleh hasil bahwa sebesar 25.675 penumpang $(34,47 \%)$ membayar tarif lebih besar dari seharusnya dan sebesar $48.803(65,53 \%)$ membayar tarif lebih kecil dari seharusnya.

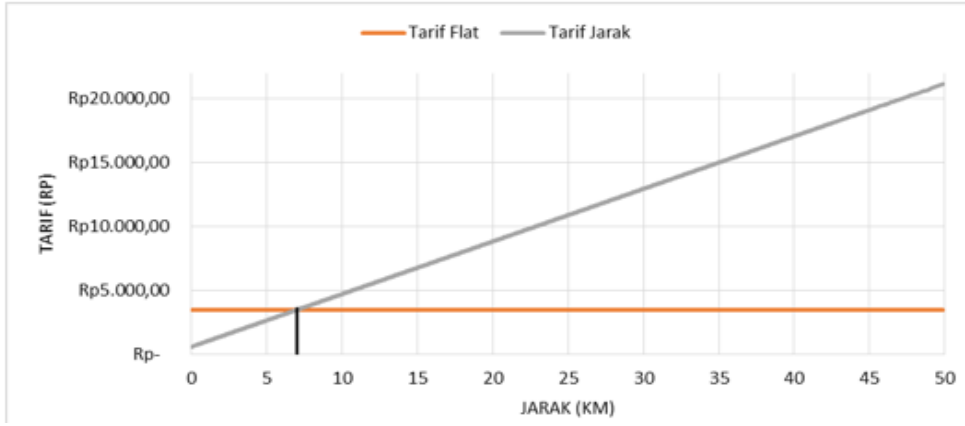

Gambar 5. Perbandingan Struktur Tarif Flat dan Struktur Tarif Berdasarkan Jarak

Dengan menggunakan data distribusi frekuensi dan asumsi penerapan struktur tarif berdasarkan jarak juga dapat diketahui bagaimana perbandingan revenue yang diperoleh jika menggunakan struktur tarif flat sebesar Rp.3.500 dan struktur tarif berdasarkan jarak dengan konsep BPA pada penetapan besaran tarifnya yang dapat dilihat pada Gambar 6.

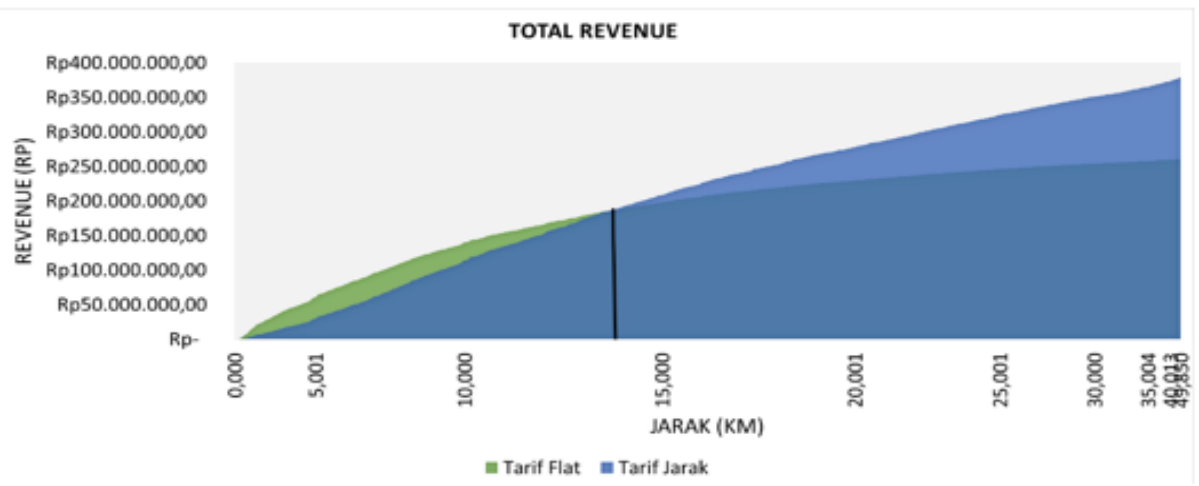

Gambar 6. Perbandingan Total Revenue Pada Penerapan Struktur Tarif Flat dan Struktur Tarif Berdasarkan Jarak

Titik pertemuan antara kedua garis tersebut merepresentasikan jarak dimana revenue yang diperoleh oleh kedua penerapan struktur tarif tersebut kurang lebih bernilai sama yaitu pada jarak 13,704 km. Berdasarkan gambar di atas dapat terlihat bahwa penerapan struktur tarif flat dapat dikatakan menguntungkan pada jarak perjalanan di bawah 13,704 km sedangkan 
untuk perjalanan jarak jauh yang lebih dari $13,704 \mathrm{~km}$ penerapan struktur tarif berdasarkan jarak jauh lebih menguntungkan. Dengan membandingkan penerapan kedua jenis struktur tarif tersebut dapat disimpulkan bahwa jika menerapkan struktur tarif distance-based pada pengoperasian Transjakarta dengan konsep BPA dalam penerapan besaran tarifnya akan menghasilkan revenue yang lebih besar $45,58 \%$ jika dibandingkan dengan penerapan struktur tarif flat.

\section{Analisis Ability to Pay}

Berdasarkan hasil perhitungan ATP diperoleh hasil bahwa untuk penumpang jarak terdekat dengan rata-rata perjalanan 2,5 km/trip nilai ATP adalah sebesar Rp.3915,85/Km. Sedangkan untuk jarak penumpang terjauh dengan rata-rata perjalanan 47,5 km/trip nilai ATP adalah sebesar Rp.205,71/km. Berdasarkan grafik ATP di atas, dapat diketahui bahwa dengan nilai ATP minimal sebesar Rp.205,71/Km artinya seluruh penumpang Transjakarta (persentil $100 \%$ ) saat ini masih mampu untuk menggunakan layanan Transjakarta jika terjadi perubahan tarif. Sedangkan jika menggunakan nilai ATP sebesar Rp.781,92/Km artinya hanya sekitar 75\% dari penumpang Transjakarta saat ini yang mampu menggunakan layanan Transjakarta jika terjadi perubahan tarif. Pada penelitian ini, untuk menentukan besaran tarif dari kebijakan struktur tarif yang akan dibuat didasarkan pada tujuan agar seluruh penumpang Transjakarta saat ini masih mampu menggunakan layanan Transjakarta setelah terjadi perubahan tarif. Berdasarkan hal tersebut, maka dalam penelitian ini akan menggunakan nilai ATP persentil 100\% yaitu Rp.205,71/km. Adapun hasil perhitungan ATP dapat dilihat pada Gambar 7.

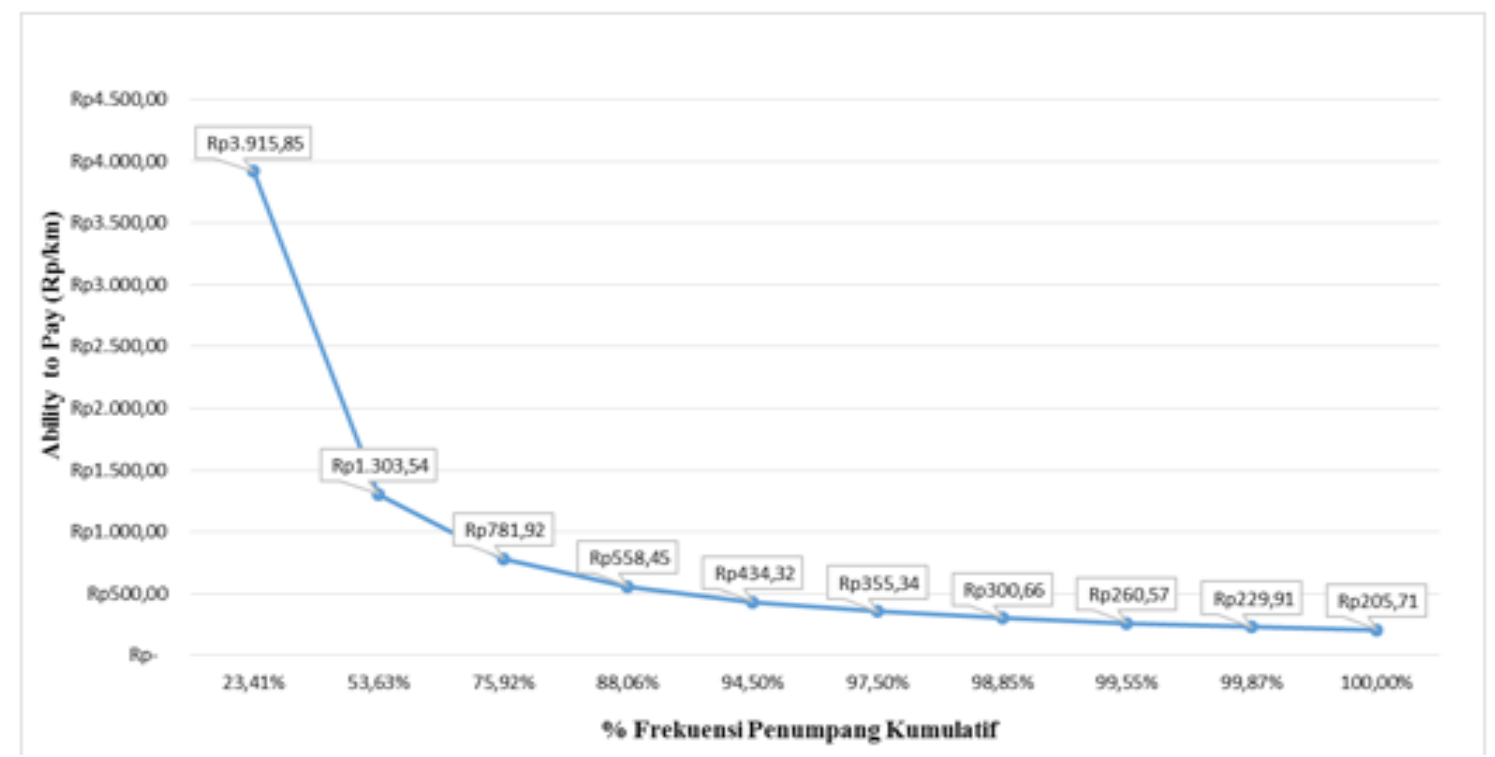

Gambar 7. Grafik Ability To Pay (ATP) untuk Setiap Kilometer Penumpang di Provinsi DKI Jakarta

\section{Perumusan Alternatif Kebijakan dan Perhitungan Revenue}

Dengan menggunakan nilai ATP persentil 100\% sebesar Rp.205,71/km dapat ditentukan seberapa besar tarif maksimal yang mampu dibayarkan oleh pengguna untuk jarak perjalanan terjauh. Tarif maksimal tersebut akan menjadi batasan (constrain) dalam perumusan alternatif kebijakan. 


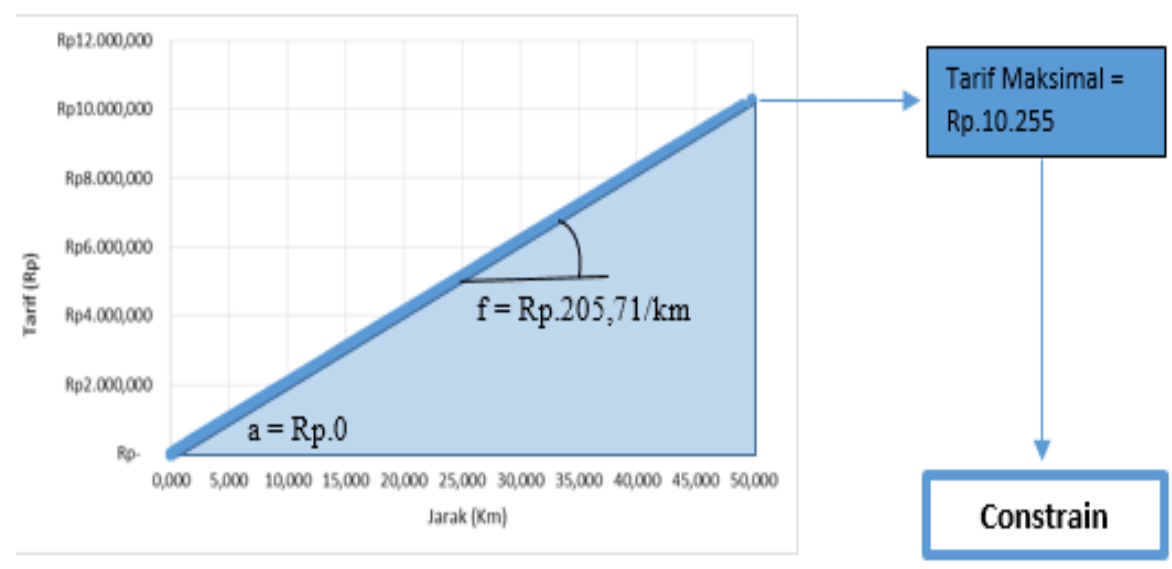

Gambar 8. Penerapan Ability To Pay (ATP) untuk Menentukan Besaran Tarif Maksimum

Berdasarkan gambar di atas, dapat diketahui bahwa jika menggunakan struktur tarif berdasarkan jarak dengan tarif awal a = Rp.0 dan tarif penyesuaian (f) sebesar Rp.205,71/Km maka untuk perjalanan terjauh dengan jarak 49,85 km penumpang harus membayar sebesar Rp.10.255. Dalam analisis kebijakan struktur tarif Transjakarta ini memiliki goals atau objective function untuk memaksimalkan total revenue Transjakarta, sedangkan besarnya ATP pengguna menjadi batasannya (constrain).

Adapun pertimbangan-pertimbangan yang dilakukan dalam perumusan alternatif kebijakan struktur tarif adalah sebagai berikut:

1. Tarif pada jarak lintasan terjauh harus kurang dari Rp.10.255.

2. Besarnya tarif awal (a) maksimal adalah Rp.3500 dengan pertimbangan agar tidak mempengaruhi elastisitas permintaan penumpang.

3. Jarak maksimum penerapan tarif awal (a) pada alternatif kebijakan struktur tarif bertahap adalah 15 kilometer pertama.

4. Jarak antar section setelah kenaikan pertama (tarif awal) berkisar antara 5 - 15 kilometer.

5. Besarnya tarif penyesuaian (f) pada alternatif kebijakan struktur tarif bertahap adalah Rp.500 s/d Rp. 2.000

Berdasarkan hal tersebut maka alternatif kebijakan struktur tarif dengan karakteristik spasial yang dapat dirumuskan adalah sebagai berikut:

Tabel 1. Rumusan Alternatif Kebijakan yang Akan Dianalisis

\begin{tabular}{|c|l|}
\hline $\begin{array}{c}\text { No } \\
\text { Alt }\end{array}$ & \multicolumn{1}{|c|}{ Alternatif } \\
\hline 0 & Struktur Tarif Flat \\
\hline 1 & $\begin{array}{l}\text { Struktur Tarif Berdasarkan Jarak (distance-based) de ngan tarif awal Rp.3.500 dan tarif pe nyesuaian } \\
\text { Rp.135/km }\end{array}$ \\
\hline 2 & $\begin{array}{l}\text { Struktur Tarif bertahap dengan Tarif Awal Rp. } 3500 \text { Berlaku pada } 10 \mathrm{~km} \text { Pertama kemudian bertambah } \\
\text { se besar Rp.2000 untuk setiap } 15 \mathrm{~km}\end{array}$ \\
\hline 3 & $\begin{array}{l}\text { Struktur Tarif bertahap dengan Tarif Awal Rp. } 3500 \text { Berlaku pada } 15 \mathrm{~km} \text { Pertama kemudian bertambah } \\
\text { se besar Rp.900 untuk setiap } 5 \mathrm{~km}\end{array}$ \\
\hline 4 & $\begin{array}{l}\text { Struktur Tarif bertahap dengan Tarif Awal Rp. } 3500 \text { Berlaku pada } 15 \mathrm{~km} \text { Pertama kemudian bertambah } \\
\text { se besar Rp.1500 untuk setiap } 10 \mathrm{~km}\end{array}$ \\
\hline 5 & $\begin{array}{l}\text { Struktur Tarif bertahap dengan Tarif Awal Rp. } 3500 \text { Berlaku pada } 10 \mathrm{~km} \text { Pertama kemudian bertambah } \\
\text { se besar Rp.1500 untuk setiap } 10 \mathrm{~km}\end{array}$ \\
\hline 7 & $\begin{array}{l}\text { Struktur Tarif bertahap dengan Tarif Awal Rp. } 3500 \text { Berlaku pada } 10 \mathrm{~km} \text { Pertama kemudian bertambah } \\
\text { se besar Rp.800 untuk setiap } 5 \mathrm{~km}\end{array}$ \\
\hline
\end{tabular}


Berdasarkan tabel di atas, dapat dilihat bahwa terdapat 7 (tujuh) alternatif yang terdiri dari 1 (satu) kebijakan struktur tarif distance-based dan 6 (enam) struktur tarif bertahap/sectional fare yang telah dirumuskan.

Pada masing-masing alternatif kebijakan tersebut akan dihitung besarnya revenue dan persentase jumlah penumpang yang mengalami kenaikan tarif (membayar lebh besar dari biasanya) dengan menggunakan jumlah penumpang dari data tapping pada tanggal 18 Mei 2018 yaitu sebesar 74.478 penumpang. Adapun rekapitulasi dari hasil perhitungan revenue dan persentase jumlah penumpang yang mengalami kenaikan tarif untuk masing-masing alternatif dapat dilihat pada Tabel 2.

Tabel 2. Rekapitulasi Perhitungan Total Revenue untuk Seluruh Alternatif Kebijakan

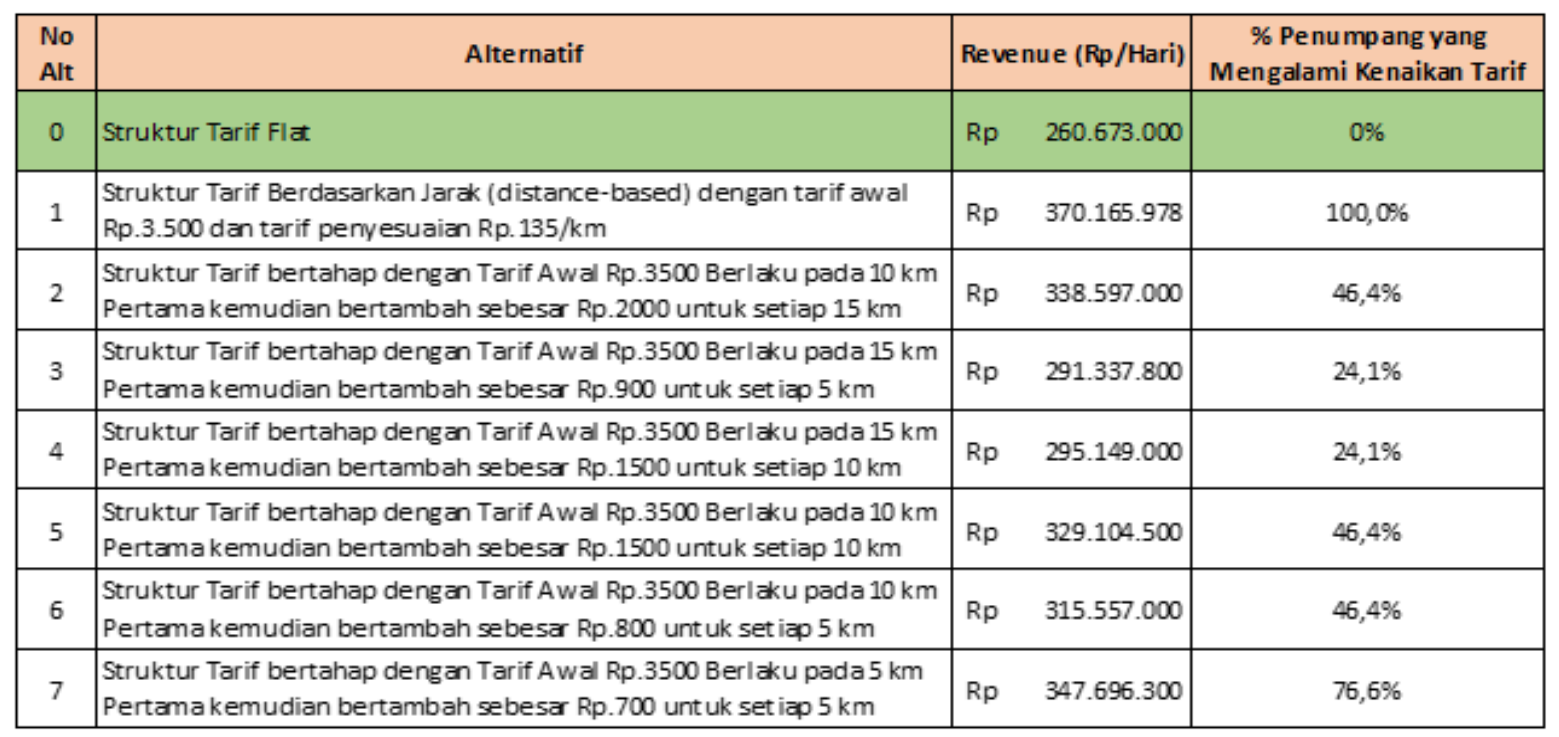

\section{Evaluasi dan Pemilihan Alternatif Kebijakan Struktur Tarif}

Dalam menentukan kebijakan struktur tarif terbaik dari seluruh alternatif kebijakan yang telah dirumuskan sebelumnya dilakukan dengan cara evaluasi menggunakan metode Simple Aditif Weighting (SAW) yang sering juga disebut dengan metode penjumlahan terbobot.

Berdasarkan hasil evaluasi yang telah dilakukan pada masing-masing alternatif kebijakan struktur tarif, dapat diketahui nilai akhir pada masing-masing alternatif struktur tarif dengan kriteria penurunan besaran subsidi dan persentase penumpang yang mengalami kenaikan tarif. Jika pengambilan keputusan hanya didasarkan pada kriteria penurunan besaran subsidi saja maka alternatif tebaik adalah alteratif 1 yaitu kebijakan struktur tarif berdasarkan jarak (distance-based fare) dengan tarif awal Rp.3.500 kemudian berlaku tarif penyesuaian sebesar Rp.135/km karena mampu menghasilkan penurunan besaran subsidi sebesar Rp.109.492.978/hari atau sekitar 34,01\% jika dibandingkan struktur tarif flat. Sedangkan jika pengambilan keputusan hanya dilihat dari sisi persentase penumpang yang mengalami kenaikan tarif menjadi lebih besar dari biasanya maka alternatif terbaik adalah alternatif 3 atau alternatif 4 yaitu struktur tarif bertahap dengan tarif awal sebesar Rp.3.500 yang berlaku pada 15 kilometer pertama karena penumpang yang mengalami kenaikan tarif hanya sebesar $24,1 \%$.

Jika melihat dari kedua kepentingan dengan cara melakukan pembobotan menggunakan metode SAW, maka alternatif kebijakan struktur tarif yang paling sesuai untuk diterapkan oleh Transjakarta adalah alternatif 4 yaitu kebijakan struktur tarif bertahap/sectional fare dengan tarif awal Rp.3.500 yang berlaku pada 15 kilometer pertama kemudian berlaku tarif penyesuaian sebesar Rp.1.500 untuk setiap pertambahan jarak 10 kilometer karena dapat menghasilkan penurunan besaran subsidi sebesar Rp.34.476.000/hari atau sekitar 10,71\% jika 
dibandingkan dengan struktur tarif flat dan memiliki persetase penumpang yang mengalami kenaikan tarif menjadi lebih besar dari biasanya sekitar $24,1 \%$ saja.

\section{KESIMPULAN}

Berdasarkan analisis dan evaluasi yang telah dilakukan dalam penelitian ini, maka diperoleh beberapa kesimpulan sebagai berikut :

1. Dengan menggunakan data distribusi frekuensi penumpang yang diperoleh dari data tapping Transjakarta pada tanggal 18 Mei 2018 dan membandingkan penerapan struktur tarif flat dan struktur tarif berdasarkan jarak (distance-based fare) menggunakan konsep biaya pokok armada dalam penetapan besaran tarifnya diperoleh hasil bahwa dengan penerapan struktur tarif flat pada Transjakarta mengakibatkan sebesar 34,47\% penumpang harus membayar tarif yang lebih besar dari seharusnya. Sedangkan jika dilihat dari segi peningkatan total revenue Transjakarta, diperoleh hasil bahwa penerapan struktur tarif flat dapat dikatakan menguntungkan pada jarak perjalanan di bawah 13,704 $\mathrm{km}$ sedangkan untuk perjalanan jarak jauh yang lebih dari 13,704 km penerapan struktur tarif berdasarkan jarak jauh lebih menguntungkan karena dapat menghasilkan total revenue yang lebih besar $45,58 \%$ jika dibandingkan dengan penerapan struktur tarif flat.

2. Alternatif kebijakan struktur tarif yang dapat diterapkan oleh Transjakarta adalah sebagai berikut :

- Alternatif 1 : Struktur tarif berdasarkan jarak (distance-based fare) dengan tarif awal Rp.3.500 kemudian langsung berlaku tarif penyesuaian sebesar Rp.135/km. Penerapan alternatif tersebut menghasilkan revenue sebesar Rp.370.165.978/hari dan persentase jumlah penumpang yang mengalami kenaikan tarif sebesar $100 \%$.

- Alternatif 2 : Struktur tarif bertahap (sectional fare) dengan tarif awal Rp.3.500 berlaku pada 10 kilometer pertama kemudian berlaku tarif penyesuaian sebesar Rp.2000 untuk setiap pertambahan jarak 15 kilometer. Penerapan alternatif tersebut menghasilkan revenue sebesar Rp.338.597.000/hari dan persentase jumlah penumpang yang mengalami kenaikan tarif sebesar $46,4 \%$.

- Alternatif 3 : Struktur tarif bertahap (sectional fare) dengan tarif awal Rp.3.500 berlaku pada 15 kilometer pertama kemudian berlaku tarif penyesuaian sebesar Rp.900 untuk setiap pertambahan jarak 5 kilometer. Penerapan alternatif tersebut menghasilkan revenue sebesar Rp.291.337.800/hari dan persentase jumlah penumpang yang mengalami kenaikan tarif sebesar $24,1 \%$.

- Alternatif 4 : Struktur tarif bertahap (sectional fare) dengan tarif awal Rp.3.500 berlaku pada 15 kilometer pertama kemudian berlaku tarif penyesuaian sebesar Rp.1500 untuk setiap pertambahan jarak 10 kilometer. Penerapan alternatif tersebut menghasilkan revenue sebesar Rp.295.149.000/hari dan persentase jumlah penumpang yang mengalami kenaikan tarif sebesar $24,1 \%$.

- Alternatif 5 : Struktur tarif bertahap (sectional fare) dengan tarif awal Rp.3.500 berlaku pada 10 kilometer pertama kemudian berlaku tarif penyesuaian sebesar Rp.1500 untuk setiap pertambahan jarak 10 kilometer. Penerapan alternatif tersebut menghasilkan revenue sebesar Rp.329.104.500/hari dan persentase jumlah penumpang yang mengalami kenaikan tarif sebesar $46,4 \%$.

- Alternatif 6 : Struktur tarif bertahap (sectional fare) dengan tarif awal Rp.3.500 berlaku pada 10 kilometer pertama kemudian berlaku tarif penyesuaian sebesar Rp.800 untuk setiap pertambahan jarak 5 kilometer. Penerapan alternatif tersebut menghasilkan revenue sebesar Rp.315.557.000/hari dan persentase jumlah penumpang yang mengalami kenaikan tarif sebesar $46,4 \%$. 
- Alternatif 7 : Struktur tarif bertahap (sectional fare) dengan tarif awal Rp.3.500 berlaku pada 5 kilometer pertama kemudian berlaku tarif penyesuaian sebesar Rp.700 untuk setiap pertambahan jarak 5 kilometer. Penerapan alternatif tersebut menghasilkan revenue sebesar Rp.347.696.300/hari dan persentase jumlah penumpang yang mengalami kenaikan tarif sebesar 76,6\%.

3. Berdasarkan proses evaluasi menggunakan metode SAW yang telah didlakukan, diperoleh hasil bahwa alternatif yang dianggap paling tepat untuk diterapkan oleh transjakarta sesuai dengan kriteria yang ditetapkan adalah alternatif 4 atau alternatif kebijakan struktur tarif bertahap (sectional fare) dengan tarif awal Rp.3.500 berlaku pada 15 kilometer pertama kemudian berlaku tarif penyesuaian sebesar Rp.1500 untuk setiap pertamabhan jarak 10 kilometer. Penerapan alternatif tersebut dapat menghasilkan penurunan besaran subsidi sebesar Rp.34.476.000/hari atau sekitar 10,71\% jika dibandingkan struktur tarif flat dan hanya mempengaruhi sekitar $24,1 \%$ penumpang yang mengalami kenaikan tarif menjadi lebih besar dari biasanya.

\section{DAFTAR PUSTAKA}

Beasley, J \& Grimsey, C, (1991). "Fares policy: the public interest". 49 $9^{\text {th }}$ UITP International Conggres. Stockholm.

Cervero, R. (1980). "Flat versus differentiated transit pricing: what's a fair fare?". IURD Working Paper Series, No. 337. University of California Berkeley. Berkeley.

Daskin, M.S., Schofer, J.L., \& Haghani A.E. (1988). "A Quadratic Programming Model for Designing and Evaluating Distance-Based and Zone Fares for Urban Transit". Transportation Research, 22B, pp. 25-44.

Dewita, Y, Yen, BTH \& Burke, M (2017). "Beyond The Cost/Income Ratio: New Approaches to Measuring Transport Affordability in Three Indonesian Metropolitan Regions". Australian Transport Research Forum, 27 - 29 November 2017. Auckland. New Zealand.

Glaeser, E.L., Kahn, M.E., \& Rappaport, J. (2008). "Why do the poor live in cities? The role of public transportation". Jurnal of Urban Economy, Vol. 63, No. 1, pp. 1-24, <http://dx.doi.org/10.1016/j.jue.2006.12.004>.

Ling, J.H. (1998). "Transit Fare Differentials: A Theoritical Analysis". Jurnal of Advanced Transportation, Vol.32, No.3, pp. 297-314. Cheng Kung University, Taiwan.

Liu, B.Z, G, YE, Cao K, Jiang X, Meng L, Liu D, et al. (2017). "Optimizing a Desirable Fare Structure for a Bus-Subway Corridor". Plos One 12 (10): e 0184815, <https://doi.org/10.1371/journal.pone0184815>.

Muhtadi, A., Wasono, S.B., Suprayitno \& Ahyudanari (2019). "Potential Number of Passenger and Performance Evaluation of Surabaya School Bus". Jurnal of Infrastructure \& Facility Asset Management, 1(2), September 2019.

Nuworsoo, C, Deakin, E \& Golub, A. (2009). "Analyzing Equity Impacts of Transit Fare Change: Case Study of Alameda -Contra Costa Transit". University of California Transportation Center. Berkeley. California.

Soemitro, R.A.A. \& Suprayitno, H. (2018). "Pemikiran Awal tentang Prinsip Dasar Manajemen Aset Fasilitas". Jurnal Manajemen Aset Infrastruktur \& Fasilitas, Vol.2, Suplemen 1, Juni 2018.

Tamin, O.Z, dkk. (1999). "Evaluasi Tarif Angkutan Umum dan Analisis 'Ability to Pay' dan Analisis 'Willingness to Pay' di DKI Jakarta". Jurnal Transportasi FSTPT, Vol. 1, No. 2, Desember 1999.

Taylor, B, \& Morris, E. (2015). "Public transportation objectives and rider demographics: are transit's priorities for poor public policy?". Transportation Vol. 42, No. 2, pp. 347-367. <http://dx.doi.org/10.1007/s11116-014-9547-0>. 
Upa V.A., Suprayitno, H. \& Ryansyah, M. (2018). "Perbandingan dan Sintesia Karakteristik Perilaku Perjalanan Pengguna Bis Trans Maminasata dan Bis Trans Koetaradja". Jurnal Manajemen Aset Infrastruktur \& Fasilitas, Vol. 2, No. 2, September 2018.

Verbich, D \& Ahmed, EG. (2015). Public Transit Fare Structure and Social Vulnerability in Montreal, Canada. McGill University. Montreal. Canada.

Vuchic, VR, (2005). Urban Transit Operation, Planning and Economics. John Wiley \& Son.Inc. Canada.

Warpani, S, (2002). Pengelolaan Lalu Lintas dan Angkutan Jalan. Penerbit ITB. Bandung. 


\section{(e)ISSN 2615-1847 (p)ISSN 2615-1839}

Jurnal Manajemen Aset Infrastruktur \& Fasilitas - Vol. 4, No. 3, Juli 2020 